\title{
Üçgen Kuyu Potansiyeli ile Modellenen Ar ve Xe Akışkanlarının Termodinamik Özellikleri
}

\author{
Enes YILDIRIM ${ }^{1 *}$, Mustafa KOYUNCU ${ }^{2}$ \\ *Sorumlu yazar: Enes-yildirim-27@outlook.com \\ ${ }^{1}$ Selçuk Üniversitesi, Fen Bilimleri Enstitüsü, Fizik Ana Bilim Dalı, KONYA \\ Orcid No: 0000-0003-2668-6998 / Enes-yildirim-27@outlook.com \\ ${ }^{2}$ Selçuk Üniversitesi, Fen Fakültesi, Fizik Bölümü, KONYA \\ Orcid No: 0000-0001-5409-9171 / mkoyuncu@selcuk.edu.tr
}

\begin{abstract}
Öz: İkinci mertebeli Barker-Henderson pertürbasyon teorisine dayalı olarak üçgen kuyu potansiyeli için türetilen analitik durum denklemi Ar ve Xe akışkanlarının sıvı buhar dengesi, basınç ve iç enerji gibi termodinamik özelliklerinin hesaplanmasında kullanılmıştır. Elde edilen sonuçlar hem simülasyon hem de deneysel veriler ile karşılaştııılmıştır. Her iki akışkan için sıvı buhar dengesi için elde edilen sonuçların kritik nokta yakındaki bölge haricinde hem deney hem de simülasyon verileriyle uyumlu olduğu görülmüştür. Diğer taraftan basınç ve enerji sonuçları için bazı uyumsuzlukların ortaya çıktı̆̆ı gözlenmiştir.
\end{abstract}

Anahtar Kelimeler: Durum denklemi, Termodinamik özellikler, Pertürbasyon teorisi, Buhar-sıvı dengesi

Thermodynamic Properties of Ar and Xe Fluids Modeled by Triangular Well Potential

\begin{abstract}
The simple analytical equation of state derived for the triangular well potential based on the second order Barker-Henderson perturbation theory is used to calculate the thermodynamic properties such as liquid-vapor equilibrium, pressure and internal energy of $\mathrm{Ar}$ and Xe fluids. Obtained results were compared with both simulation and experimental data. It was seen that the results obtained for liquid-vapor equilibria for both fluids were compatible with both the experimental and the simulation data except for the region near the critical point. On the other hand, it has been observed that some incompatibilities occur for pressure and energy results.
\end{abstract}

Keywords: Equation of state, Thermodynamic properties, Perturbation theory, Vapour-liquid equilibria

\section{Giriș}

İstatistiksel mekaniğin temel amaçlarından biri, moleküler sistemlerin termodinamik özelliklerini sistemi oluşturan parçacıklar arasındaki etkileşim potansiyeli üzerinden hesaplamaktır (Nezbeda, 2001; Barcenas ve ark., 2015; Guerin, 2015). Bu, gerçek etkileşim potansiyeli kesin olarak bilinemediğinden genellikle model potansiyeller kullanarak pertürbasyon teorileri, integral denklemi teorileri ve bilgisayar simülasyonları (Monte Carlo ve moleküler dinamik) gibi farklı teknikler kullanarak gerçekleştirilir (Barcenas ve ark., 2015). Üçgen-kuyu (TW) potansiyeli, basit gerçek akışkanların termodinamik özelliklerini ve buhar-sıvı faz geçişini doğru bir şekilde modelleyebilen basit bir model potansiyeldir (Largo ve Solana, 2000; Trejos ve ark., 2018). Her ne kadar TW potansiyeli, bir diğer basit model olan kare-kuyu potansiyelinden daha gerçekçi bir potansiyel 
olsa da gerek teorik gerekse de bilgisayar simülasyonları aracılığı ile yeterince incelenmemiştir. Dolayısıyla termodinamik özellikleri hakkında yeteri bilgiye (veriye) sahip olunmadığı düşünülmektedir. $\mathrm{Bu}$ nedenle son yillarda üçgen-kuyu potansiyelin gerek termodinamik gerekse de taşınım özellikleri üzerindeki çalışmalarda görece bir artış gözlenmektedir.

TW potansiyeli ilk olarak 1940 yılında bir boyutlu akışkanları modellemek üzere Nagamiya (1940) tarafindan tanımlanmış ve bir sıvı-buhar faz geçişi gösterdiği belirtilmiştir. TW potansiyeli için ilk simülasyon çalışması $\lambda=2$ potansiyel menzili için $0.8 \leq T^{*} \leq 5$ indirgenmiş sicaklık ve $0.14 \leq \rho^{*} \leq 0.86$ indirgenmiş yoğunluk aralığında durum denklemi, iç enerji ve radyal dağılım fonksiyonu (RDF) verilerini elde etmek için Card ve Walkley (1974) tarafından yapılmıştır. Elde edilen veriler ayrıca Barker-Henderson (BH) (1967) ve Weeks-Chandler-Andersen (WCA) (Weeks ve ark., 1971) pertürbasyon teorilerini test etmek amaciyla kullanılmış, yüksek yoğunluk bölgesinde WCA yaklaşımının, düşük yoğunluk bölgesinde ise $\mathrm{BH}$ yaklaşımının daha iyi sonuçlar verdiği bulunmuştur. TW potansiyelinin gerçek sistemlere ilk uygulaması, farklı mikro emülsiyonların Rayleigh oranlarının hesaplandığ 1 ve deneysel verilerle karşılaştırıldığı çalışma ile yapılmıştır (Somasekhara Reddy ve Murthy, 1983).
Largo ve Solana (2000), referans katı küre (HS) sistemine ait Chang ve Sandler (1994) tarafından türetilen analitik RDF ifadesini ikinci mertebeli $\mathrm{BH}$ pertürbasyon teorisinde kullanarak TW akışkanının termodinamik özellikleri için yoğunluk, sıcaklık ve potansiyel menzilinin fonksiyonu olan analitik ifadeler elde etmişlerdir. Elde edilen sonuçların simülasyon verileri ile uyumlu olduğunu ve ayrıca, $(\varepsilon, \sigma, \lambda)$ potansiyel parametrelerinin ayarlanabilir parametreler olarak ele alınmasıyla basit gerçek akışkanların durum denkleminin analitik olarak ifade edilebileceğini belirtmişlerdir. Adhikari ve Kofke (2002), TW model sisteminin buhar-sıv1, kat1-sıv1 ve kat1-kat1 birlikte bulunma eğrisi sınırlarını $1.05 \leq$ $\lambda \leq 2.5$ çekim menzili aralığında belirlemek için Monte Carlo simülasyonları ve hücre modeli hesaplamaları yapmışlardır. Wang ve Lai (2002), van der Waals benzeri bir teori bağlamında kısa menzilli çekici TW potansiyeli için faz diyagramını inceledikleri çalışmada, etkileşim menzili ve şiddetinin siv1-sıv1, sıv1-kat1 ve kat1-katı faz diyagramları üzerinde oynadığı rolü araştırmışlardır. Betancourt-Cardenas ve ark. (2007), TW akışkanı için BH pertürbasyon teorisini kullanarak kuyu genişliği, yoğunluk ve sıcaklığın fonksiyonu olarak $1.1 \leq \lambda \leq 2$ aralığında uygulanabilen analitik bir durum denklemi türetmişlerdir. Ayrıca Helmholtz serbest enerji açılımındaki birinci ve ikinci mertebeli terimlere ilave 
olarak termodinamik özellikleri Gibbs kümesi ve NPT Monte Carlo simülasyonları ile de elde etmişler, teori ve simülasyon sonuçlarının karşılaştırmasını yapmışlardır. Betancourt-Cardenas ve ark. (2008), tarafından yapılan diğer bir çalışmada ise uzun menzilli $(\lambda=2.5,3.0,4.0) \mathrm{TW}$ akışkanının termodinamik özellikleri üç farklı yaklaşımla (pertürbasyon teorisi, öz uyumlu Ornstein-Zernike integral teorisi ve GEMC simülasyonu) incelenmiştir. Ayrıca, modelin gerçek akışkanları temsil etme kabiliyetini test etmek amaciyla metan ve etan için durum denklemi ile yapılan hesaplama sonuçları deneysel verilerle karşılaştırılmış ve mükemmel uyum bulunmuştur.

Zhou (2009), TW potansiyelinin ve yoğunluğa bağlı versiyonunun termodinamiğini ve faz davranışını incelemek için çiftlenim parametresi açılımına dayalı bir termodinamik pertürbasyon teorisi (TPT) kullanmış ve bilgisayar simülasyonu ile üretilen verilerle karşılaştırıldığında beşinci dereceden TPT'nin hem sayısal olarak kararlı hem de nitel olarak doğru en iyi performans1 gösterdiğini ortaya koymuştur. Koyuncu (2011), uzun menzilli üçgen kuyu akışkanı (LR-TW) için analitik durum denklemini kısa menzilli çekici Yukawa potansiyelini referans alarak genişletilmiş van der Waals teorisine dayalı olarak türetmiştir. Elde edilen durum denklemi, sıv1-buhar faz diyagramı ve termodinamik özelliklerin belirlenmesinde kullanılmış, literatür verileri ile uyumlu sonuçlar elde edilmiştir. Guerin (2012), TW akışkanı için makroskopik sıkışabilirlik yaklaşımına dayalı $\mathrm{BH}$ pertürbasyon teorisi kullanılarak BetancourtCardenas ve ark. (2007) tarafindan türetilen durum denklemini daha doğru bir HS RDF kullanarak basit analitik forma indirgemiştir. Rivera ve ark. (2012), TW akışkanın durum denklemini, katı küre akışkanının radyal dağ $11 ı$ fonksiyonu için rasyonel fonksiyon yaklaşımını kullanarak ikinci mertebeli $\mathrm{BH}$ pertürbasyon teorisine dayalı olarak elde etmişler ve farklı potansiyel menzilleri için sivı-buhar faz dengesi ve kritik parametre hesaplamaları yapmışlardır. Orea ve Odriozola (2013) ve Barcenas ve ark. (2015), TW akışkanının faz birlikteliği ve arayüz özelliklerini farklı çekim menzilleri için Monte Carlo ve moleküler dinamik simülasyonları ile incelemişlerdir. Sengupta ve Adhikari (2016), Büyük kanonik kümede geçiş matrisi Monte Carlo (GC-TMMC) simülasyonlarını çekim menzilinin akışkan faz dengesi üzerindeki rolünü araştırmak için kullanmışlardır. TW potansiyelinin menzili artarken, buhar-sıvı bir arada var olma eğrilerinin artan kritik sicaklık ve basınca, azalan kritik yoğunluğa sahip olacak şekilde daha yüksek bir sıcaklık aralığına doğru kaydığını gözlemlemişlerdir. Reyes ve ark. (2016), TW potansiyelinin sıvı-buhar faz diyagramını ve arayüz 
gerilimini farklı etkileşme menzilleri için MC ve MD simülasyonları ile iki boyutta hesaplamışlar, her iki simülasyon sonucunun birbirleriyle uyumlu olduğunu bulmuşlardır. Barcenas ve ark. (2017), kolloidal süspansiyonların faz davranışını geniş bir sıcaklık aralığında Monte Carlo Raplica Exchance (REMC) simülasyonu ile inceledikleri çalışmada kısa menzilli $(1.15 \leq \lambda \leq 1.4) \quad$ TW potansiyelini kullanmışlardır. TW akışkanlarının ve protein süspansiyonlarının faz davranışı arasında nitel bir uyumun olduğunu, dolayısıyla protein süspansiyonlarının bazı termodinamik özelliklerinin TW potansiyeli ile hesaplanabileceğini ve anlaşılabileceğini ifade etmişlerdir. Benavides ve ark. (2018), TW potansiyeli için $(\sigma, \epsilon, \lambda)$ potansiyel parametreleri ile sıcaklık ve yoğunluğa açık bir şekilde bağlı analitik bir durum denklemini elde etmek için kesikli pertürbasyon teorisini (DPT) kullanmışlardır. Durum denkleminin $\lambda>$ 1.2 olmak kaydıyla geniş bir aralıkta doğru olduğunu, sıvı-buhar faz diyagramaları, iç enerji ve basınçlar için elde edilen sonuçların kritik nokta yakınındakiler dışında mevcut simülasyon verileri ile uyumlu olduğunu ifade etmişlerdir. Trejos ve ark. (2018), TW akışkanının termodinamik özelliklerini belirlemek için kullandıkları durum denklemini yine BarkerHenderson pertürbasyon teorisine dayalı olarak türetmişler, $\quad(1.2 \leq \lambda \leq 2.6)$ aralığında Monte Carlo simülasyon verileriyle uyumlu sonuçlar elde etmişlerdir. Teorik yaklaşımı geniş bir sıcaklık ve basınç aralığında metan, oksijen, florometan ve hidrojen sülfür gibi gerçek akışkanları modellemek için kullanmışlardır. Montero ve Santos (2019), TW potansiyeli ile etkileşen parçacıkların bir boyutlu sıvılarının hem termodinamik hem de yapısal denge özelliklerinin tam istatistiksel-mekanik çözümlemesini yaptıkları çalışmada, RDF için istenilen herhangi bir mesafe için kullanılabilecek tam bir analitik ifade elde etmişlerdir. Çözümü, durum denklemi, parçacık başına artık iç enerji, artık çok parçacık entropisi, yap1 faktörü, RDF ve direkt korelasyon fonksiyonunu incelemek için kullanmışlardır.

Bu çalışmada Trejos ve ark. (2018), tarafından TW potansiyeli için $\mathrm{BH}$ pertürbasyon teorisine dayalı olarak türetilen analitik durum denklemi $\mathrm{Ar}$ ve $\mathrm{Xe}$ akışkanlarının termodinamik özelliklerini ve faz davranışını belirlemek için kullanılmıştır. Elde edilen sonuçlar deneysel veriler ve faklı teorik çalışmalardan elde edilen sonuçlarla karşılaştırılmıştır.

\section{Materyal ve Metot}

\subsection{TW Sıvıları için BH Pertürbasyon Teorisi}

Pertürbasyon teorileri, özellikle saf akışkanların termodinamik özelliklerinin belirlenmesinde en sik kullanılan 
yöntemlerden biridir. $\mathrm{Bu}$ teoriler, türetilmesi hâlen açı bir problemdir akışkanların termodinamik özelliklerinin (Akhouri ve Solana, 2020).

başlıca itici etkileşmeler tarafından Parçacıkları arasındaki etkileşimleri $u(r)$ belirlendiği, çekici etkileşmelerin ise pertürbasyon olarak alınabileceği kabulüne dayalıdır. İtici etkileşme katkısı, termodinamik ve yapısal özellikleri bilinen bir referans akışkanından elde edilebilir. $\mathrm{Bu}$ teoriler grubu içinde, yüksek sıcaklık açılımı olarak bilinen ve serbest enerjinin mutlak sicaklığın tersine göre kuvvet serisi açılımına dayanan teoriler öne çıkar. Zwanzig (1954), tarafından önerilen bu açılımda, sıfırıncı mertebeli terim, referans akışkanın katkısı olup basit akışkanlar durumunda genellikle HS akışkanı ile temsil edilir. Basit akışkanlar için birinci mertebeli pertürbasyon terimi, referans akışkanının durum denklemi ve radyal dağılım fonksiyonuna bağlı olarak doğru bir şekilde belirlenebilir. İkinci dereceden terim için ise özellikle yüksek yoğunluk ve düşük sıcaklık bölgesinde yeterince doğru olmayan birkaç teorik yaklaşım geliştirilmiştir (Barker ve Henderson, 1967; Weeks ve ark., 1971). İkinci dereceden terim için ampirik düzeltmeler de teklif edilmiştir ancak bunlar da geniş bir potansiyel menzili aralığı için tatmin edici sonuçlar sağlamamaktadır (Zhang, 1999; Paricaud, 2006). Daha yüksek dereceli terimlerin elde edilmesi çok daha zordur ve kabul edilebilir bir doğruluk ve basitlik derecesine sahip bir teorinin küresel simetrik potansiyeli ile tanımlanan bir akışkan göz önüne alındığında, potansiyel

$u(r)=u_{o}(r)+u_{1}(r)$

şeklinde iki kısma ayrılabilir. Pertürbasyon teorisinde potansiyelin baskın k1smı olan $u_{o}(r)$, referans potansiyel, $u_{1}(r)$ ise referans potansiyelin pertürbasyonu olarak göz önüne alınır. HS sisteminin termodinamik ve yapısal özellikleri neredeyse tümüyle bilindiğinden yaygın olarak kullanılan bir referans potansiyelidir:

$u_{o}(r)=u^{H S}(r)= \begin{cases}\infty, & r<\sigma \\ 0, & r \geq \sigma\end{cases}$

$\mathrm{Bu}$ ifadede $r$, parçacıkların merkezleri arasındaki uzaklık $\sigma$ ise parçacık çapıdır. BH pertürbasyon teorisine göre parçacıkları TW potansiyeli ile etkileşen bir sistem için, çekici katkı yani pertürbasyon kısmı;

$u_{1}(r)=u^{a t t}(r)=\left\{\begin{array}{cl}0, & r<\sigma, \\ -\frac{\varepsilon(\lambda-r)}{(\lambda-\sigma)}, & \sigma \leq r<\lambda \\ 0, & r \geq \lambda\end{array}\right.$

şeklinde ifade edilir. Burada $\varepsilon$ ve $\lambda$ sırasıyla potansiyelin enerji derinliği ve menzilidir. $\mathrm{BH}$ pertürbasyon teorisine göre $u(r)$ 
potansiyeli iki katkıya ayrıldıktan sonra Helmholtz serbest enerjisi $(A)$

$$
\frac{A}{N k_{B} T}=\frac{A^{i d}}{N k_{B} T}+\frac{A^{e x c}}{N k_{B} T}
$$

formunda ifade edilir (Barker ve Henderson, 1967). Burada $N$ sistemdeki parçacık sayısı, $k_{B}$ Boltzmann sabiti ve $T$ mutlak sicaklıktır. $A^{\text {id }}$ ve $A^{\text {exc }}$ sirasiyla ideal ve artık Helmholtz serbest enerjisidir. İdeal gazın serbest enerjiye katkıs1

$$
\frac{A^{i d}}{N k_{B} T}=\ln \left(\rho \lambda_{B}^{3}\right)-1
$$

ile verilir ve burada $\lambda_{B}$ de Broglie dalga boyu, $\rho$ sistemin yoğunluğudur. Artık serbest enerji, parçacıklar arasındaki farklı etkileşmelerden kaynaklanan katkılardan oluşur. Dolayısıyla,

$$
\frac{A^{e x c}}{N k_{B} T}=\frac{A^{H S}}{N k_{B} T}+\frac{A^{a t t r}}{N k_{B} T} \ldots
$$

şeklinde ifade edilebilir (Trejos ve ark., 2018). HS akışkanının serbest enerjisi genellikle, Carnahan-Starling durum denkleminden elde edilen

$$
\frac{A^{H S}}{N k_{B} T}=\frac{4 \eta-3 \eta^{2}}{(1-\eta)^{2}}
$$

ifadesi ile verilir (Carnahan ve Starling, 1969). Burada $\eta=\pi \rho \sigma^{3} / 6$ ile verilen paketlenme kesri, $\quad \rho=N / V \quad$ say1 yoğunluğudur. $\quad$ Yüksek sicaklık yaklaşımında çekici Helmholtz serbest enerjisi $A^{a t t r}$, sicaklığın tersine göre kuvvet açılımı ile temsil edilebilir;

$$
\frac{A^{\text {attr }}}{N k_{B} T}=\beta \frac{A_{1}}{N k_{B} T}+\beta^{2} \frac{A_{2}}{N k_{B} T}+\cdots
$$

Burada $\beta=1 / k_{B}$ T ve $A_{i}$ katsayıları $i=$ $1,2, \ldots, n$ olmak üzere $\mathrm{BH}$ pertürbasyon teorisinin $i$. mertebeli pertürbasyon terimleridir. Üçüncü ve daha yüksek mertebeli terimlerin kesin olarak hesaplanmasındaki güçlükler ve ayrıca ilk iki mertebeli terimle karşılaştırıldıklarında katkılarının oldukça az olması dikkate alınarak açılım genellikle ikinci mertebede kesilir yani $O\left(\beta^{3}\right)$ mertebeli terimler ihmal edilir (Espidola-Heredia ve ark., 2009).

Helmholtz serbest enerjisine birinci mertebeli katk1 $A_{1}$,

$$
\frac{A_{1}}{N k_{B} T}=2 \pi \rho \int_{\sigma}^{\infty} \mathrm{g}^{H S}(r) u^{a t t}(r) r^{2} d r
$$

ile verilir ki burada $\mathrm{g}^{H S}(r)$, HS akışkanının radyal dağılım fonksiyonudur. "Lokal sıkıştırılabilirlik yaklaşımı" (LCA) olarak adlandırılan yaklaşım altında ikinci mertebeli pertürbasyon terimi,

$$
\frac{A_{2}}{N k_{B} T}=-\pi K^{H S} \rho \frac{\partial}{\partial \rho}\left[\rho \int_{\sigma}^{\infty} \mathrm{g}^{H S}(r)\left[u^{a t t}(r)\right]^{2} r^{2} d r\right]
$$


şeklinde verilir. Burada $K^{H S}=$ $k_{B} T\left(\partial \rho / \partial P^{H S}\right)_{T}$ HS akışkanının izotermal sıkıştırılabilirliği olup Perkus-Yevick ifadesine göre

$$
K^{H S}=\frac{(1-\eta)^{4}}{1+4 \eta+4 \eta^{2}}
$$

ile verilir (Barker ve Henderson, 1976).

Helmholtz serbest enerjisinin paketlenme kesrinin fonksiyonu olarak analitik ifadesi bilindikten sonra, basınç $(P)$, kimyasal potansiyel $(\mu)$, sıkıştırılabilirlik çarpanı (Z) (yani durum denklemi) vb. termodinamik değişkenleri standart termodinamik bağıntılar aracılığıyla belirlenebilir.

$$
\begin{aligned}
& P=-\left(\frac{\partial A}{\partial V}\right)_{T, N} \\
& \mu=\left(\frac{\partial A}{\partial N}\right)_{T, V} \\
& Z \equiv \frac{P V}{N k_{B} T}=\frac{1}{k_{B} T}\left(\frac{\partial A}{\partial N}\right)_{T, V}-\frac{A}{N k_{B} T} \\
& \frac{U}{N k_{B} T}=-T \frac{\partial}{\partial T}\left(\frac{A}{N k_{B} T}\right)_{V, N}
\end{aligned}
$$

Herhangi bir etkileşim aralığı için belirli bir sıcaklıktaki sıv1 $(l)$ ve buhar $(v)$ fazları arasındaki termodinamik denge, her bir faz için kimyasal $\left(\mu^{l}=\mu^{v}\right)$, mekanik $\left(P^{l}=P^{v}\right)$ ve termal denge $\left(T^{l}=T^{v}\right)$ şartları çözülerek elde edilebilir. $\mathrm{Bu}$

denklemleri sağlayan tüm noktalar $\rho-T$ düzleminde binodal çizgiyi oluşturur.

\subsection{Hesaplamada Kullanılan} Analitik İfadeler

Helmholtz serbest enerjisine ait birinci ve ikinci mertebeli terimlerin (9) ve (10) eşitliklerine göre hesaplanabilmesi için HS akışkanına ait uygun bir RDF ifadesine ihtiyaç vardır. Hâlihazırda literatürde mevcut olan HS RDF ifadeleri genellikle sayısal hesaplama yapmayı zorunlu kılar ancak farklı yaklaşımlar kullanarak analitik ifadeler elde etmek de mümkündür. Trejos ve ark. (2018), TW akışkanı için analitik bir durum denklemi elde etmek için öncelikle (9) ve (10) eşitliklerini Chang ve Sandler (1994) tarafından teklif edilen HS RDF için sayısal olarak çözmüşler, daha sonra bir paketlenme kesri parametrizasyonu teklif etmişlerdir. Türetimin detaylarına ilgili makalede ulaşılabileceğinden burada tekrar yer verilmeyecek, yalnızca hesaplamalarda kullanılan temel ifadeler kisaca ele alınacaktır. $x=r / \sigma$ indirgenmiş mesafe ve $\xi$ ortalama değer teoremini karşılayan bir mesafe olmak üzere birinci ve ikinci mertebeli terimler için sırasıyla

$$
\begin{aligned}
\frac{A_{1}}{N k_{B} T} & =-\epsilon \eta \mathrm{g}^{H S}(\xi ; \eta)\left(\lambda^{3}+\lambda^{2}+\lambda-3\right) \\
\frac{A_{2}}{N k_{B} T} & =\frac{2}{11} \frac{\lambda \epsilon}{(\lambda-1)} K^{H S} \eta \frac{\partial}{\partial \eta}\left(\frac{A_{1}}{N k_{B} T}\right)
\end{aligned}
$$


elde edilmiştir. Burada $\mathrm{g}^{H S}(\xi ; \eta), \eta_{\text {eff }}$ etkin paketlenme kesri cinsinden tanımlanan RDF olup

$$
\mathrm{g}^{H S}(\xi ; \eta)=\mathrm{g}^{H S}\left(1 ; \eta_{\mathrm{eff}}\right)
$$

şeklinde tanımlanmış, radyal dağılım fonksiyonunun $x=\sigma$ daki temas değeri olan $\mathrm{g}^{H S}\left(1 ; \eta_{\mathrm{eff}}\right)$ için ise

$$
\mathrm{g}^{H S}\left(1 ; \eta_{\mathrm{eff}}\right)=\frac{\left(1-\frac{\eta_{\mathrm{eff}}}{2}\right)}{\left(1-\eta_{\mathrm{eff}}\right)^{3}}
$$

Carnahan-Starling ifadesi kullanılmıştır. $\eta_{\text {eff }}$ için

$$
\begin{aligned}
& \eta_{\text {eff }}=c_{1} \eta+c_{2} \eta^{2}+c_{3} \eta^{3} \\
& \left(\begin{array}{l}
c_{1} \\
c_{2} \\
c_{3}
\end{array}\right)=\left(\begin{array}{ccc}
1,94785 & -1,03659 & 0,14141 \\
2,65578 & -3,37315 & 0,85580 \\
-2,83219 & 2,92387 & -0,66341
\end{array}\right)\left(\begin{array}{c}
1 \\
\lambda \\
\lambda^{2}
\end{array}\right)
\end{aligned}
$$

parametrizasyon elde edilmiştir (Trejos ve ark., 2018). $A_{1}$ ve $A_{2}$ için elde bu ifadeler aracalığıyla TW akışkanının termodinamik özelliklerinin analitik olarak belirlenmesini sağlamış olur.

\subsection{Termodinamik Özellikler}

Farklı potansiyel menzili ve yoğunluk değerleri için TW akışkanına ait $A_{1}, A_{2}$, artık iç enerji, basınç ve sıvı-buhar birlikte bulunma eğrisi hesaplamaları Trejos ve ark. (2018) tarafından yapılmış ve mevcut literatür verileriyle karşılaştırılmış olduğundan burada tekrar edilmemiştir. Çalışmanın asıl amacı durum denkleminin gerçek sistemlerin termodinamik davranışını temsil etme kabiliyetini test etmek olduğundan, hesaplamalar Ar ve Xe basit akışkanları için yapılmıştır. Sonuçlar, farklı teorik yaklaşımlar, bilgisayar simülasyonu yöntemleri ve deneysel olarak elde edilen verilerle karşılaştırılmıştır. $\mathrm{Bu}$ çalışmada, Barcenas ve ark. (2015) tarafindan TW potansiyeli ile modellenen $\mathrm{Ar}$ ve $\mathrm{Xe}$ akışkanlarının sıvı-buhar birlikte bulunma eğrisi ve yüzey geriliminin Monte Carlo simülasyonu ile LJ potansiyelini en iyi şekilde taklit edecek şekilde seçilen potansiyel parametreleri kullanılmış ve Tablo 1 de verilmiştir.

Tablo 1. Ar ve Xe için moleküler parametreler: HS çapı $(\sigma)$, çekim menzili $(\lambda)$ ve potansiyel derinliği $(\epsilon)$.

\begin{tabular}{|l|l|l|l|}
\hline Akışkan & $\lambda$ & $\sigma[\mathrm{nm}]$ & $\epsilon / k_{B}[\mathrm{~K}]$ \\
\hline $\mathbf{A r}$ & 2.045 & 3.3952 & 116.79 \\
\hline $\mathbf{X e}$ & 2.030 & 3.9011 & 227.55 \\
\hline
\end{tabular}

\section{Araştırma Sonuçları}

\subsection{Sivi-buhar dengesi}

Ar ve Xe için sıv1-buhar dengesine ait hesaplama sonuçları literatür verileri ile birlikte Şekil 1 de verilmiştir. Sürekli çizgi bu çalışmanın sonuçlarını, deneysel veriler NIST webbook dan, simülasyon sonuçları ise Mick ve ark. (2015) ve Marcelli ve Sadus (1999), tarafindan yapilan çalışmalardan alınmıştır. Mick ve ark. (2015), optimize Mie n-6 potansiyelleri (genelleştirilmiş Lennard-Jones 12-6 potansiyeli) ile modelledikleri asal gazların sıv1-buhar dengesini büyük kanonik kümede 
Monte Carlo simülasyonu ile ikinci virial katsayılarına ve moleküler 1 şın hesaplamışlardır. $\sigma, \varepsilon$ ve $n$ potansiyel şaçılma verilerine fit işleminden parametreleri her bir asal gaz için deneysel doymuş sıvı yoğunlukları ve buhar basınçları verilerini eş zamanlı olarak \%1 \%4 aralığında doğrulukla verecek şekilde optimize edilmiştir. Marcelli ve Sadus (1999) tarafindan Gibbs kümesinde Monte Carlo simülasyonu ile yapılan çalışmada, Barker ve ark.(1971; 1974), tarafından Argon ve Xe için teklif edilen farklı potansiyel ifadeleri kullanılmıştır. Çok sayıda parametre içeren bu potansiyel fonksiyonlarındaki parametreler deneysel belirlenmiştir. Şekil 1'den açıkça görüleceği üzere hiçbir potansiyel fonksiyonunun gerek Ar gerekse de Xe için sıvı-buhar dengesini tam olarak ortaya koyduğu söylenemez. Hal denkleminden elde edilen sonuçların her iki kol için özellikle yüksek sıcaklık bölgesinde simülasyon ve deneysel verilerden bir miktar saptığı gözlense de genel davranışın kabul edilebilir düzeyde olduğu söylenebilir. Özellikle kritik nokta yakınında deneysel verilerden olan sapma tüm sonuçlar için benzer niteliktedir.
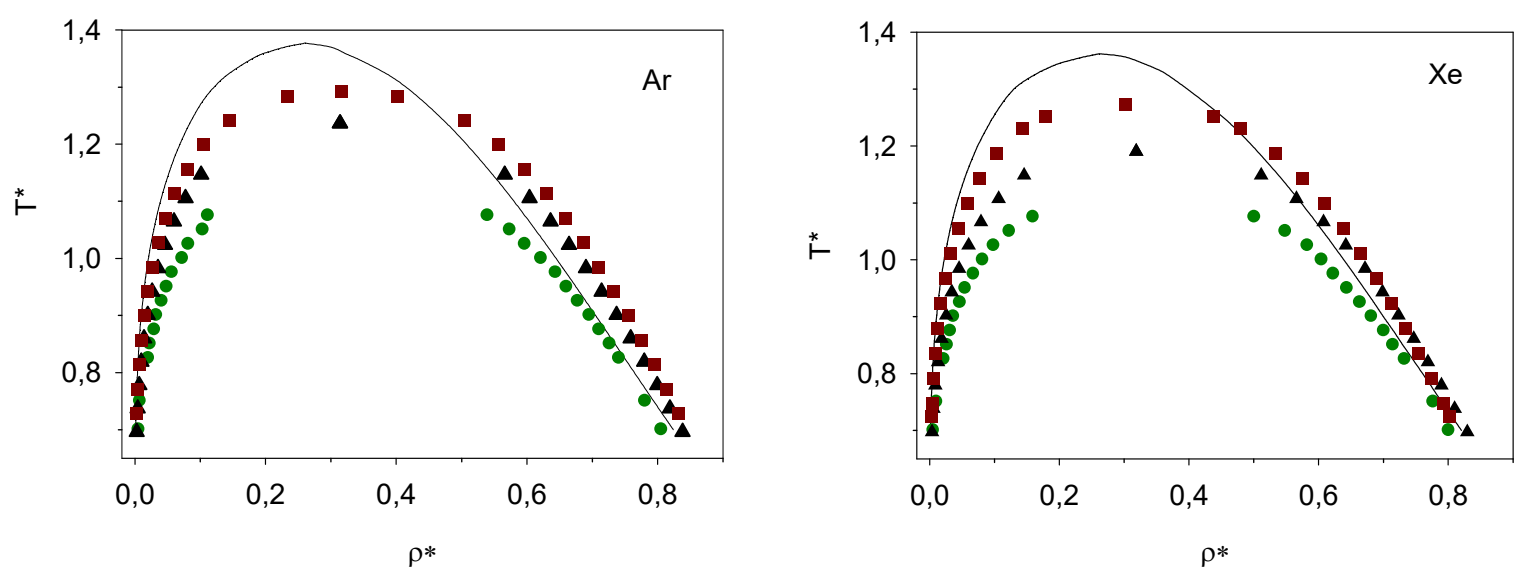

Şekil 1. TW potansiyeli ile modellenen Argon ve Xenon için sıv1-buhar birlikte bulunma eğrisi. (一) düz çizgi TW-EOS sonuçlarını, semboller ise sırasıyla simülasyon ve deney verilerini temsil etmeketedir: (•) (Marcelli ve Sadus, 1999), ( $\boldsymbol{\Delta}$ ) (Mick ve ark., 2015), (घ) NIST ChemistryWebBook.

\section{2. İndirgenmiş enerji ve basınç}

Argon ve xenon için farkl indirgenmiş sıcaklık $\left(T^{*}=k T / \varepsilon\right) \quad$ ve yoğunlukta $\left(\rho^{*}=\rho \sigma^{3}\right)$ indirgenmiş enerji $\left(U^{*}=U / \varepsilon\right)$ ve indirgenmiş basınç $\left(P^{*}=\right.$ $P \sigma^{3} / \varepsilon$ ) için yapılan hesaplama sonuçları, deney ve simülasyon verileri ile birlikte sırasıyla Tablo 2 ve Tablo 3'de verilmiştir.
Deney ve simülasyon verileri Goharshadi ve Abbaspour (2006) tarafindan yapilan çalışmadan alınmıştır. Argon ve xenon akışkanlarına ait indirgenmiş enerji ve basınç için NVT kümesinde moleküler dinamik simülasyonu ile yapilan hesaplamada, HFD (Hartree-Fock dispersiyon) benzeri çift potansiyel enerji 
fonksiyonları, indirgenmiş viskozite çarpışma integrallerinin sıfır basınçta inversiyonu ile belirlenmişstir. Aynen Barker ve ark. $(1971 ; 1974)$ tarafindan teklif edilen potansiyel fonksiyonu ifadelerine benzer olarak HFD benzeri potansiyel fonksiyonu da çak sayıda parametreye sahiptir. Argon için Tablo 2'de verilen sonuçların karşılaştırılmasından açıkça görüleceği üzere indirgenmiş basınç için gerek simülasyon gerekse de bu çalışmada durum denklemi ile elde edilen sonuçların deneysel verilerden olan sapmasının özellikle düşük sıcaklık ve düşük yoğunluk bölgesinde büyük olduğu, yüksek sıcaklık ve düşük yoğunluk bölgesinde ise simülasyon sonuçlarının deneysel verilerle uyumunun durum denkleminden elde edilenlerden daha iyi olduğu görülmektedir. Durum denkleminden elde edilen sonuçların deneysel verilerle olan uyumundan ziyade simülasyon sonuçları ile uyum içinde olması beklenen bir sonuçtur. Simülasyon ve durum denkleminden elde edilen sonuçlar arasındaki uyumsuzluğun en önemli nedenlerinden biri her iki yöntemde kullanılan potansiyel fonksiyonlarının farklı olması olabilir. Simülasyonda kullanılan potansiyel fonksiyonu hesaplamada kullanılan potansiyel fonksiyonuna kıyasla neredeyse etkin bir potansiyel olma kabiliyetine sahiptir. Ayrıca pertürbasyon teorisinin doğasında var olan kabul ve yaklaşımların da bu uyumsuzluğun ortaya çıkmasında etkin olması mümkündür. İndirgenmiş enerji sonuçlarının karşılaştırılmasında simülasyon sonuçlarının beklenildiği üzere deneysel verilerle daha uyumlu olduğu, hesaplama sonuçlarının ise hem simülasyon hem de deneysel verilerden daha düşük olduğu görülecektir.

Tablo 2. Argon için farklı indirgenmiş sıcaklık ve indirgenmiş yoğunlukta farklı yöntemlerle elde edilen indirgenmiş basınç ve enerji

\begin{tabular}{|c|c|c|c|c|c|c|c|}
\hline $\mathbf{T}^{*}$ & $\boldsymbol{\rho} *$ & $\boldsymbol{P}^{*}$ exp. & $U^{*} \exp$ & $P *_{\text {sim. }}$ & $U^{*}$ sim. & $\boldsymbol{P}^{*}{ }_{e o s}$ & $U^{*}{ }_{e o s}$ \\
\hline 0,7441 & 0,7368 & 0,1306 & $-3,3053$ & 0,4882 & $-3,3537$ & 0,6325 & $-4,7184$ \\
\hline 0,8185 & 0,6803 & 0,0495 & $-2,8176$ & 0,2498 & $-2,8655$ & 0,4535 & $-4,1143$ \\
\hline 0,8365 & 0,0326 & 0,0223 & 0,9598 & 0,0231 & 1,0058 & 0,0281 & 1,1977 \\
\hline 0,8433 & 0,6663 & 0,0631 & $-2,6847$ & 0,2365 & $-2,7304$ & 0,4513 & $-3,9520$ \\
\hline 0,8681 & 0,6534 & 0,0820 & $-2,5586$ & 0,2536 & $-2,5953$ & 0,4571 & $-3,7976$ \\
\hline 0,8783 & 0,0383 & 0,0270 & 0,9863 & 0,0277 & 1,0280 & 0,0340 & 1,2249 \\
\hline 0,8929 & 0,6346 & 0,0805 & $-2,4005$ & 0,2117 & $-2,4371$ & 0,4160 & $-3,5961$ \\
\hline 0,9177 & 0,6087 & 0,0658 & $-2,2058$ & 0,1640 & $-2,2368$ & 0,3362 & $-3,3394$ \\
\hline 0,9201 & 0,5967 & 0,0437 & $-2,1360$ & 0,1247 & $-2,1629$ & 0,2741 & $-3,2396$ \\
\hline 0,9425 & 0,5958 & 0,0893 & $-2,0831$ & 0,1764 & $-2,1064$ & 0,3466 & $-3,1850$ \\
\hline 0,9619 & 0,0843 & 0,0533 & 0,7663 & 0,0561 & 0,8300 & 0,0657 & 0,9627 \\
\hline 0,9673 & 0,5601 & 0,0720 & $-1,8407$ & 0,1188 & $-1,8437$ & 0,2434 & $-2,8501$ \\
\hline 0,9921 & 0,5094 & 0,0659 & $-1,5673$ & 0,0769 & $-1,5269$ & 0,1337 & $-2,3977$ \\
\hline $\mathbf{1 , 0 0 3 7}$ & 0,1023 & 0,0644 & 0,7184 & 0,0666 & 0,7676 & 0,0784 & 0,8906 \\
\hline 1,0456 & 0,1201 & 0,0763 & 0,6811 & 0,0795 & 0,7467 & 0,0918 & 0,8242 \\
\hline
\end{tabular}


Tablo 3. Xenon için farklı indirgenmiş sıcaklık ve indirgenmiş yoğunlukta farklı yöntemlerle elde edilen indirgenmiş basınç ve indirgenmiş enerji.

\begin{tabular}{|c|c|c|c|c|c|c|c|}
\hline$T^{*}$ & $\rho *$ & $P^{*} \exp$ & $U^{*}{ }_{\exp }$ & $P^{*}{ }_{s i m}$ & $U^{*}{ }_{s i m}$ & $\boldsymbol{P}^{*}{ }_{\text {eos }}$ & $U^{*}{ }_{e o s}$ \\
\hline 0,7466 & 0,7073 & 0,0212 & 0,8778 & $-1,1673$ & $-2,1472$ & 0,2025 & $-4,2312$ \\
\hline 0,8212 & 0,6722 & 0,0899 & 1,2419 & $-0,9493$ & $-1,9212$ & 0,3042 & $-3,8042$ \\
\hline 0,8461 & 0,6351 & 0,0275 & 1,4850 & $-0,8736$ & $-1,7617$ & 0,1747 & $-3,4701$ \\
\hline 0,8710 & 0,6181 & 0,0338 & 1,6454 & $-0,7873$ & $-1,6775$ & 0,1781 & $-3,2873$ \\
\hline 0,8959 & 0,6001 & 0,0476 & 1,7963 & $-0,7631$ & $-1,5814$ & 0,1781 & $-3,0970$ \\
\hline 0,9208 & 0,5790 & 0,0578 & 1,9612 & $-0,6631$ & $-1,4835$ & 0,1683 & $-2,8841$ \\
\hline 0,9457 & 0,5179 & 0,0546 & 2,1906 & $-0,4951$ & $-1,2467$ & 0,0581 & $-2,3687$ \\
\hline 0,9705 & 0,5119 & 0,0637 & 2,4064 & $-0,4603$ & $-1,2120$ & 0,1003 & $-2,2691$ \\
\hline
\end{tabular}

verilen sonuçlar karşılaştırıldığı zaman simülasyonla elde edilen basınç değerlerinin tüm sıcaklık ve yoğunluk aralığında negatif olduğu, durum denkleminden elde edilen sonuçların ise tersine olarak pozitif olduğu görülmektedir. Enerji için ise hem simülasyon hem de durum denklemi ile yapılan hesaplamalarından elde edilen sonuçların her ikisi de negatif, deneysel veriler ise pozitiftir. En azından simülasyon ve hesaplama sonuçları nitel olarak uyum içindedir. Bu noktada her iki potansiyel fonksiyonunun da xenon akışkanını modellemede başarısız olduğunu söylemek mümkündür.

\section{Tartışma}

Bu çalışmada, Trejos ve ark. (2018) tarafından üçgen kuyu potansiyeli için ikinci mertebeli $\mathrm{BH}$ pertürbasyon teorisine dayalı olarak türetilen analitik durum denklemi $\mathrm{Ar}$ kullanılmıştır. Elde edilen sonuçlar hem simülasyon hem de deneysel veriler ile karşılaştırılmıştır. Her iki akışkan için sıvı buhar dengesi için elde edilen sonuçların kritik nokta yakındaki bölge haricinde hem deney hem de simülasyon verileriyle uyumlu olduğu görülmüştür. Diğer taraftan basınç ve enerji sonuçları için bazı uyumsuzluklar gözlenmiştir. Ortaya çıkan bu uyumsuzluğun başlıca sebeplerinden biri kullanilan durum denkleminin türetilmesinde kullanılan potansiyel fonksiyonunun yalnızca iki cisim etkileşmelerini içermesi olabilir. Üç ya da daha fazla cisim etkileşmelerini içeren bir potansiyel fonksiyonunun kullanılması durumunda sonuçlarda iyileşme beklenebilir. Pertürbasyon teorisinin ikinci mertebede kesilmesinin de sonuçlar üzerindeki etkisinin incelenmesi gerekir. 
Pertürbasyon teorilerinde etkileşme yarı-deneysel (Aziz-Slaman, Barker-Fisherpotansiyeline ilave olarak en önemli Watts, BFW vb.) veya $a b$ initio (Jögeretkenlerden bir diğeri de radyal dağılım Hellmann-Bich-Vogel, JHB vb.) fonksiyonudur. Trejos ve ark. (2018) potansiyelleri grubunda yer alan (Deiters ve tarafından kullanılan radyal dağılım Sadus, 2019) spesifik potansiyeller, fonksiyonu yerine daha gerçekçi bir radyal matematiksel olarak oldukça karmaşık dağılım fonksiyonu kullanılması da sonuçlar yapıya sahip olduklarından analitik üzerinde olumlu etkiye yol açabilecektir.

Elbette, hem buhar-sıvı dengesi hem de basınç ve enerji veya burada dikkate alınmayan diğer termodinamik özellikler için daha iyi sonuçların elde edilebilmesine imkân sağlayabilme potansiyeline sahip spesifik potansiyel fonksiyonlarının kullanılması da mümkündür. Ancak belirli hesaplamalar için çok uygun değildirler. Diğer taraftan, hemen hemen her tür akışkana uygulanabilen üçgen-kuyu, karekuyu, Lennard-Jones (12-6), Yukawa, Buckingham (exp-6), Kihara vb. potansiyelleri geneldir ve $a b$ initio veya yar1-deneysel potansiyellerine göre analitik hesaplamaya daha uygundurlar.

bir atom ya da atom grubuna ait olan ve

\section{Kaynaklar}

Adhikari J, Kofke DA (2002). Monte Carlo and cell model calculations for the solid-fluid phase behaviour of the triangle-well model. Mol Phys 100: 1543-1550.

Akhouri BP, Solana JR (2020). Square-well mixtures revisited: computer simulation, mixing rules and one-fluid theory. Molec Sim 46: 102-110.

Barcenas M, Castellanos V, Reyes Y, Odriozola G, Orea P (2017). Phase behaviour of short range triangle well fluids: A comparison with lysozyme suspensions. J Mol Liq 225: $723-729$.

Barcenas M, Reyes Y, Romero-Martínez A, Odriozola G, Orea P (2015). Coexistence and interfacial properties of a triangle-well mimicking the Lennard-Jones fluid and a comparison with noble gases. J Chem Phys 142: 074706.

Barker JA, Henderson D (1967). Perturbation theory and equation of state for fluids: the square-well potential. J Chem Phys 47: 2856-2861.

Barker JA, Henderson D (1976). What is liquid? Understanding the states of matter. Rev Mod Phys 48: 587-671.

Barker JA, Fisher RA, Watts RO (1971). Liquid argon: Monte Carlo and molecular dynamics calculations. Mol Phys 21: 657-673.

Barker JA, Watts RO, Lee JK, Schafer TP, Lee YT (1974). Interatomic potentials for krypton and xenon. J Chem Phys 61: 3081-3089.

Benavides AL, Cervantes LA, Torres-Arenas J (2018). Analytical equations of state for triangle-well and triangle-shoulder potentials. J Molec Liq 271: 670-676. 
Betancourt-Cardenas FF, Galicia-Luna LA, Sandler SI (2007). Thermodynamic properties for the triangular-well fluid. Mol Phys 105: 298-2998.

Betancourt-Cardenas FF, Galicia-Luna LA, Benavides AL, Ramirez JA, Schöll-Paschinger E (2008). Thermodynamics of a long-range triangle-well fluid. Mol Phys 106: 113-126.

Card DN, Walkley J (1974). Monte Carlo and perturbation calculations for a triangular well fluid. Can J Phys 52: 80-88.

Carnahan NF, Starling KE (1969). Equation of state for nonattracting rigid spheres. $J$ Chem Phys 51: 635-636.

Chang J, Sandler SI (1994). A real function representation for the structure of the hard-sphere fluid. Mol Phys 81: 735-744.

Deiters, UK, Sadus, RJ (2019). Two-body interatomic potentials for $\mathrm{He}, \mathrm{Ne}, \mathrm{Ar}, \mathrm{Kr}$ and $\mathrm{Xe}$ from ab initio data. J Chem Phys 150: 134504.

Espíndola-Heredia, R, del Río F, Malijevsky A (2009). Optimized equation of the state of the square-well fluid of variable range based on a fourth-order free-energy expansion. $J$ Chem Phys 130: 024509.

Goharshadi EK, Abbaspour M (2006). Molecular dynamics simulation of argon, krypton, and xenon using two-body and three-body intermolecular potentials. $J$ Chem Theory and Comput 2: 920-926.

Guerin H (2012). Improved analytical thermodynamic properties of the triangular-well fluid from perturbation theory. J Mol Liq 170: 37.

Guerin H (2015). Unified SAFT-VR theory for simple and chain fluids formed of squarewell, triangular-well, Sutherland and Mie segments. J Molec Liq 203: 187-197.

Koyuncu M (2011). Equation of state of a long-range triangular-well fluid. Mol Phys 109: $565-573$.

Largo J, Solana JR (2000). A simplified perturbation theory for equilibrium properties of triangular-well fluids. Physica A 284: 68-78.

Marcelli G, Sadus RJ (1999). Molecular simulation of the phase behavior of noble gases using accurate two-body and three-body intermolecular potentials. J Chem Phys 111: 15331540 .

Mick JR, Barhaghi MS, Jackman B, Rushaidat K, Schweibert L, Potoff, JJ (2015). Optimized Mie potentials for phase equilibria: Application to noble gases and their mixtures with n-alkanes. J Chem Phys 143: 114504.

Montero AM, Santos A (2019). Triangle-well and ramp 1nteractions in one-dimensional fluids: a fully analytic exact solution. $J$ Stat Phys 175: 269-288.

Nagamiya T (1940). Statistical mechanics of one-dimensional substances I. Proc Phys-Math Soc Japan 22: 705-720.

Nezbeda I (2001). Can we understand (and model) aqueous solutions without any long range electrostatic interactions? Mol Phys 99: 1631-1639.

NIST webbook http://webbook.nist.gov/chemistry/fluid/.

Orea P, Odriozola G (2013). Constant-force approach to discontinuous potentials. J Chem Phys 138: 214105. 
Paricaud PA (2006). General perturbation approach for equation of state development: applications to simple fluids, ab initio potentials, and fullerenes. J Chem Phys124: 154505.

Reyes Y, Bárcenas M, Odriozola G, Orea P (2016). Thermodynamic properties of trianglewell fluids in two dimensions: MC and MD simulations. J Chem Phys 145: 174505.

Rivera LD, Robles M, Lopez de Haro M (2012). Equation of state and liquid-vapour equilibrium in a triangle-well fluid. Mol Phys 110: 1317-1323.

Sengupta A, Adhikari J (2016). Prediction of fluid phase equilibria and interfacial tension of triangle-well fluids using transition matrix Monte Carlo. Chem Phys 469-470: 16-24.

Somasekhara Reddy MC, Murthy AK (1983). Perturbation theory for a microemulsion with triangular well potential. Pramana 20:217.

Trejos VM, Martínez A, Valadez-Pérez NE (2018). Statistical fluid theory for systems of variable range interacting via triangular-well pair potential. J Mol Liq 265: 337-346.

Wang GF, Lai SK (2002). Phase diagram for an attractive triangular potential within van der Waals-like theory. J Non-Cryst Solids 236: 312-314.

Weeks JD, Chandler D, Andersen HC (1971). Role of repulsive forces in determining the equilibrium structure of simple liquids. J Chem Phys 41: 5237.

Zhang BJ (1999). Calculating thermodynamic properties from perturbation theory I. An analytic representation of square-well potential hard-sphere perturbation theory. Fluid Phase Equilib 154: 1-10.

Zhou S (2009). Thermodynamics and phase behavior of a triangle-well model and densitydependent variety. J Chem Phys 130: 014502.

Zwanzig RW (1954). High-temperature equation of state by a perturbation method. I. nonpolar gases. J Chem Phys 22: 1420. 